\title{
On the Integration Development of Sports Industry and Cultural Industry
}

\author{
Xuanjie Zhou, Yuntian Huang \\ Nanchang Institute of Science \&Technology, Nanchang 330108, China
}

\begin{abstract}
The core industries have similar product form and value orientation, sports industry and cultural industry are mutually dependent and complement each other. This shows a convergence mechanism for the two. It proposes the strategies for the convergence that each give full play to his strong point as well as draw success experience from each other; the establishment of coordination mechanisms, deepen the reform of regulation system, in the healthy development of fusion; focus on promoting the development of sports industry culture, connotative development; the development of cultural industry business advantages, promote the integration of sports elements with the cultural elements; increase the industrial fusion research efforts, pay attention to the training of personnel required for the development of the integration of sports and cultural industries.
\end{abstract}

Keywords: Sports Industry; Cultural Industry; Industrial Integration

\section{Introduction}

In October 2011, the CPC Central Committee put forward clearly: to promote the cultural industry and tourism, sports, information, logistics, construction and other industries development, increase the content of culture industry, the cultural industry chain extension, improve the added value. In March 2010, the State Council proposed to coordinate the development of sports industry and related industries. Give play to the comprehensive effect of sports industry and promote the stimulating effect of compound management of sports industry and culture, tourism, electronic information and other related industries, and promote the development of sports tourism, sports publishing, sports media, sports advertising, 
sports exhibition, sports video and other related formats. Therefore, how to development of sports industry and how to play the culture role of sports industry, how to increase the content of culture itself, how sports industry and cultural industry development, has become the implementation of the party and the state to promote the intention of sports industry and the prosperity, subject construction of socialist culture and sports power has great practical significance.

\section{The convergence mechanism of sports industry and cultural industry}

Through a large number of research and analysis, we think that although from a broad cultural perspective, sports is a kind of social and cultural activities, the sports industry belongs to the cultural industry has some truth, from the practice angle and relevant national authoritative documents, currently on the definition of the culture industry and are not all a large cultural industry is closely related to the industry, cultural industry should be define in parallel with the sports industry. In the reality of our country's policy context and practice, although the boundaries of sports industry and cultural industry in some areas are vague, in general, the two belong to the parallel relationship. From the practical point of view, it is logical to study the integration of sports industry and cultural industry.

The core industries news, publishing, broadcasting, film and television Arts, culture and other cultural industries and emerging industry is to provide the spirit of peripheral products as the basis, through these mental consumer products can satisfy people's spiritual and cultural needs, enrich people's spiritual world. The development of prosperity, in line with the spirit of product requirements in the construction of socialist core value system, can significantly improve the ideological and moral qualities and scientific and cultural quality, promote the all-round development of people, enhance national cultural soft power; to uphold and develop socialism with China and provides a powerful spiritual force.

In the core position of the sports industry, sports competitions, sports, leisure and fitness industry, can provide the majority of the people to watch and experience the spirit of the product. People in the consumption of these sports products, can bring spiritual enjoyment, enrich people's spiritual and cultural life, the development of these industries can also promote the construction of socialist core value system. In the cultural industry and the core position of the sports industry, the industry can provide people with spiritual and cultural products, and has a similar value orientation, become the basis of the integration of the two industries.

In fact, a lot of cultural industries, including publishing 、 media 、 film and television etc.. The development of the cultural industry can provide a platform for the formation of sports publishing, sports media, sports and other new formats, to expand the impact of sports, sports show the spiritual and cultural value, and bring financial resources for the sports industry. Especially the TV media, because of its sports for the best communication technology and means, in many 
news media advantage is more and more obvious, has become the first media to promote the development of the sports industry. In recent years, China's television media has increased the sports market and sports fitness market promotion, a large number of the introduction of foreign outstanding sports competitions and entertainment programs to promote the sports competition and leisure fitness market opening.

Television media has become one of the most important sources of funds for some large-scale events. Sports TV have become an important industrial sector with broad development prospects and value. It has become one of the important driving forces for sports to develop and make it infinite charm. In fact, these new formats and sports core industries have two different characteristics, spiritual culture is its essential attribute, sports is its explicit function, but because of historical legacy and traditional division method and other reasons, they belong to different management departments, In the industry penetration, interdisciplinary today, the two is even more difficult to distinguish between each other. For example, in practice, due to the physical fitness entertainment for the public to participate directly to promote the diversification of China's cultural market development and health and prosperity, optimizing the public leisure distribution of time and the quality of spiritual life.

Nowadays, sports programs have become one of the most popular TV programs, sports bar has become a network, newspapers and other media one of the most talked about columns, the media expansion of the audience brought about by the operation of the market, especially around the events broadcast and events news advertising industry development, for the media industry has brought huge amounts of money. Sports also promote the development of television, Internet and other communication technologies, on the television broadcast or TV screen in the use of skills slow-moving, all the performance and technology development, have the driving force of sports competitions, and continuously improve the quality of the broadcast map. Network in order to compete with the television, sports events in the video broadcast technology has also been explored and innovation.

Film and television, literary creation, cultural performances can be drawn from the nutrition, looking for creative material. With the development of sports, people not only pay attention to the intense competition, but also pay attention to the story behind the sports, concerned about the cause of athletes, life and love, pay attention to their tenacious fighting spirit, sports movies, sports TV, sports literature.

Cultural industries and the development of sports industry interrelated. Cultural industry is an important carrier of the development of sports industry, there is no cultural industry, especially the development of cultural media industry, sports will not have such a big influence today, there is no cultural connotation of the sports industry, it will lose charm, it is difficult to form the brand. Similarly, without the development of the sports industry, the cultural industry will lose a very promising market and material sources. Standing in the sports industry point of view, seize the cultural industry to seize the core values, to seize the development platform; from the cultural industry point of view, seize 
the sports industry to seize a huge market. The development of sports-related cultural industries is an important factor in the rise and fall of the sports industry and culture-related sports products is appropriate to a large extent and support the development of related cultural industries. Cultural Industry and through the interaction of subsystems, the education industry is interdependent, complementary, symbiosis, mutual promotion, and has a profound integration foundation.

\section{The strategy of convergence of sports industry and cultural industry}

It is necessary to fully tap the sports industry and cultural industry of their respective advantages, highlighting the industry special color. Cultural industry in the development of cultural content should continue to strengthen the status of the building, at the same time, accelerate platform construction. In the country, whether it is well-known television, or the famous portal websites, authoritative newspapers, etc., are based on platform to absorb innovative content. To sports communication industry is the use of the cultural industry platform communication advantages integration of sports events and other content resources to achieve the content of the cultural industry innovation and development, therefore, strengthen the platform construction, in addition to bigger and stronger cultural industry itself, but also for the whole including the content of sports, including the provision of material resources, technical basis and carrier.

Sports industries in the development process to focus on the development of the project, to create brand products as the goal, to carry out a wide range of people loved sports, and actively introduce internationally renowned sports events and brand sports and entertainment activities. To promote the combination of sports and literature and art, performing arts, media, publishing, national cultural festivals and so on, to promote the development of sports products in the spirit of civilization, build a Chinese fitness and entertainment products and well-known event brand. Through the development of core layer sports industry, the prosperity of the entire sports industry can be promoted.

Management should be fully aware of the deepening of regulatory reform is to promote industrial integration of power, legislation and government departments should adapt to the sports industry and cultural industry integration requirements, to re-examine the existing regulatory system and regulatory policies, the establishment of effective promotion of production industry integration development, with forward-looking and scientific regulatory system, and to develop appropriate of the regulatory policy.

To eliminate the barriers of industry segmentation, from the perspective of industrial integration, the establishment of new coordination mechanism is necessary. Such coordination mechanisms should be in charge of culture, advocacy and sports matters government leadership, led by the Development and 
Reform Commission, culture, sports, publicity, broadcasting, education, tourism, finance, industry and commerce and other departments responsible for coordinating the policy to achieve coordination policy, resource sharing, unified configuration. This coordinating body should have a keen market vision and grasp the overall strategic plan for the development of integration of culture and sports in accordance with the guiding ideology of "government leading, market operation, enterprise main body, social participation, mass benefit and sustainable use".

In the current process of institutional reform in some localities, the Culture Bureau and Sports Bureau merged the formation of the Culture and Sports Bureau, this body set in the streamlining of institutions. Of course, the current system also has some problems, for example, although merged into a department, but within the department of fragmented, non-cross, not to mention integration. Nevertheless, this system provides a good platform for integration; the next step is how to further running of problems.

Accelerate the legislative building, introduced to encourage industrial integration policy, to actively explore the production industry integration of enterprises and individuals to support. Industrial should be convergence after the new format, the proposal in accordance with the policy before the integration of which preferential policies on the implementation of the industry.

It is necessary to vigorously promote the integration of sports content and cultural platform, to play the cultural industry platform advantages, the use of the platform to create the brand influence of the sports industry. For example, you can make use of the characteristics of strong visual, clear picture, real-time broadcast, expand the influence of sports events and sports entertainment activities, to create brand sports products and sports entertainment products.

Promote the integration of sports elements and literary creation. The creation of literature and art should pay attention to the development of physical education, draw material from the development of sports, refine the theme, and make full use of it love, vivid, beautiful melodies, moving image, Acura sports spirit, showing the development of sports achievement, creative thought, art and appreciation of unity, loved by the people, with sports as the theme of outstanding literary works.

Relying on many universities and research institutes in China, the construction of a number of sports industry and culture industry convergence development research institutions. With these research machines for the platform, gathered a number of cultural and sports industry research personnel, tracking domestic and international cultural industry and sports industry development, planning and design integration of the development of a number of major sports industry and cultural industry development projects, to promote the development of sports industry and cultural industry integration development policy to provide information consultation and decision-making. Encourage people to vote, to carry out various types of sports industry education and cultural industries, education and training, multi-channel training not only understand the cultural industry and understand the sports industry complex talent. Colleges and universities should actively promote the reform of education and teaching; optimize the professional 
and curriculum, training to meet the needs of the development of industrial convergence.

\section{Conclusion}

Through the above analysis, we can see that in line with China's national conditions integration of sports industry and cultural industry, conform to the law of physical development; it is believed that joint efforts in the social state and society, integration development of sports industry and cultural industry will achieve good results.

\section{References:}

[1] Research on the Rise of Culture Industry and the Development of Sports Industry in Jiangsu Province[J]. Hubei Sports Science, 2013.

[2] Zhang J. On Convergence Development of Sport Industry and Culture Industry[J]. Journal of Shanghai University of Sport, 2012, 39(12):2543-2555.

[3] Cheng Y, Li T, History S O, et al. The Research on the Integration of Development of Red Tourism and Cultural Industry in Guilin[J]. Journal of Guilin Normal College, 2016.

[4] Chang W F, Tourism D O, University K. Study on the Development Strategy of Henan Cultural Tourism Industry in the Creative Perspective[J]. Journal of Kaifeng University, 2015.

[5] Jin Y, Xiaotian L I, Kaina L I. Study on the Mechanism of the Integration of Sports and Culture and Tourism Industry Based on the Perspective of Enterprise Growth [J]. Journal of Capital University of Physical Education \& Sports, 2016.

[6] Bao-Sheng W U, Dept S, Univ W. Relationship between Sports Industry and Culture Industry[J]. Journal of Sports Adult Education, 2014. 